Supporting Information

\title{
Bacteria-mediated hypoxia-specific delivery of nanoparticles for tumors imaging and therapy
}

Cheng-Hung Luo ${ }^{1}$, Chih-Ting Huang ${ }^{1}$, Chia-Hao Su${ }^{2}$, and Chen-Sheng Yeh ${ }^{1 *}$

${ }^{1}$ Department of Chemistry and Advanced Optoelectronic Technology Center, National Cheng Kung University, Tainan, Taiwan.

*Correspondence to: E-mail:csyeh@mail.ncku.edu.tw

${ }^{2}$ Center for Translational Research in Biomedical Sciences, Kaohsiung Chang Gung Memorial Hospital, Kaohsiung, Taiwan. 


\section{Experimental Procedures}

Growth of $C$. difficile strain CCUG 37780 and preparation of the spores: $C$. difficile strain CCUG 37780 was grown in an anaerobic chamber plating on the Brain-Heart Infusion agar supplied with $0.1 \%$ L-cysteine and $1 \%$ yeast extract under $37{ }^{\circ} \mathrm{C}$. To collect the spores, the bacteria were cultured in anaerobic chamber under $37^{\circ} \mathrm{C}$ for 5 days. Spores were collected by washing the bacteria with ice-cold water and resuspended in water under $4{ }^{\circ} \mathrm{C}$ for overnight. The released spores were washed with ice-cold water several times and resuspended in 50\% sucrose. Followed by centrifuged at $3000 \mathrm{rpm}$ for $30 \mathrm{~min}$, the spores were collected as pellet in the bottle of centrifugation tube.

Growth of B. breve strain UCC 2003: B. breve strain UCC 2003 was cultured on lactobacilli de Man Rogosa and Sharpe Medium (MRS) supplied with 0.05\% L-cysteine. Bacterial calculation was performed by the serial diluted bacterial suspensions and plated on dish with culture media to check the colony forming unit (CFU).

Preparation of upconversion nanorods (UCNRs), core-shell upconversion nanorods (CSUCNRs), and their surface modification for bioimaging: The synthesis of the $\mathrm{NaYF}_{4}: \mathrm{Yb}(24.7 \%), \mathrm{Tm}$ $(0.3 \%) \mathrm{NRs}$ was described as following. For the synthesis of $\mathrm{NaYF}_{4}: \mathrm{Yb}, \mathrm{Tm}, \mathrm{YCl}_{3}(0.75 \mathrm{mmol}), \mathrm{YbCl}_{3}$ $(0.247 \mathrm{mmol})$, and $\mathrm{TmCl}_{3}(0.003 \mathrm{mmol})$ were dissolved in $5 \mathrm{~mL}$ of deionized water, and then mixed with $14 \mathrm{~mL}$ of oleic acid and $5 \mathrm{~mL}$ of 1 -octadecene into a $100 \mathrm{~mL}$ flask. The solution was heated to $100{ }^{\circ} \mathrm{C}$ for $10 \mathrm{~min}\left(2{ }^{\circ} \mathrm{C} / \mathrm{min}\right)$ and degassed at $156^{\circ} \mathrm{C}$ for $30 \mathrm{~min}$, and then cooled to room temperature. A solution of $0.1482 \mathrm{~g}$ of $\mathrm{NH}_{4} \mathrm{~F}(4 \mathrm{mmol})$ and $0.1 \mathrm{~g}$ of $\mathrm{NaOH}(2.5 \mathrm{mmol})$ in $10 \mathrm{~mL}$ of methanol was added, and then the solution was kept at $50^{\circ} \mathrm{C}$ for $30 \mathrm{~min}$. Methanol was evaporated completely after heating at $75^{\circ} \mathrm{C}$ for $30 \mathrm{~min}$, and then the solution was heated to $300^{\circ} \mathrm{C}$ for $1 \mathrm{~h}$ under argon atmosphere. Subsequently, the solution was cooled to room temperature. The UCNRs were precipitated from solution by adding acetone, and then washed with hexane/ethanol, followed by centrifugation to collect sample and redispersed in hexane.

To fabricate core-shell $\mathrm{NaYF}_{4}: \mathrm{Yb}$ (24.7\%),Tm (0.3\%)@ $\mathrm{NaYF}_{4} \mathrm{NRs}, \mathrm{YCl}_{3}$ (0.5 mmol) was dissolved in $5 \mathrm{~mL}$ of deionized water, and then mixed with $14 \mathrm{~mL}$ of oleic acid and $5 \mathrm{~mL}$ of 1 -octadecene 
into a $100 \mathrm{~mL}$ flask. A solution of $0.0741 \mathrm{~g}$ of $\mathrm{NH}_{4} \mathrm{~F}(2 \mathrm{mmol})$ and $0.05 \mathrm{~g}$ of NaOH $(1.25 \mathrm{mmol})$ in 10 $\mathrm{mL}$ of methanol was added. The as-prepared $\mathrm{NaYF}_{4}: \mathrm{Yb}(24.7 \%), \mathrm{Tm}(0.3 \%)$ NRs were redispersed in hexane and the solution was kept at $50{ }^{\circ} \mathrm{C}$ for $30 \mathrm{~min}$. Methanol and hexane were evaporated completely after heating at $75{ }^{\circ} \mathrm{C}$ for $30 \mathrm{~min}$, and then the solution was heated to $300{ }^{\circ} \mathrm{C}$ for $1 \mathrm{~h}$ under argon atmosphere. Subsequently, the solution was cooled to room temperature. The CS-UCNRs were precipitated from solution by adding acetone, and then washed with hexane/ethanol, followed by centrifugation to collect sample and redispersed in hexane.

Silica-coated CS-UCNRs were prepared as following description. The UNCRs (1200 ppm, $4 \mathrm{~mL})$ in hexane $(6 \mathrm{~mL})$ were mixed with IGEPAL CO-520 $(100 \mu \mathrm{L})$ and stirred for $10 \mathrm{~min}$. Then, the transparent emulsion was formed by the addition of IGEPAL CO-520 $(400 \mu \mathrm{L})$ slowly. The solution was mixed with aqueous ammonia ( $80 \mu \mathrm{L}, 33 \%$ ) and sonicated for $20 \mathrm{~min}$. Further, $45 \mu \mathrm{L}$ of tetraethyl orthosilicate (TEOS) was added into the solution and incubated for $16 \mathrm{~h}$ with vigorous stirring. CS-UCNRs@SiO $\mathrm{S}_{2}$ were precipitated by adding acetone, and then particles were collected by centrifugation at 13,000 rpm for 20 min and washed with 50/50 ethanol/water to store in ethanol. To introduce amino groups (-NH2) on the CS-UCNRs@SiO 2 surface, the CS-UCNRs@SiO 2 (3000 ppm) in 5 mL of ethanol were mixed with 100 $\mu \mathrm{L}$ of (3-aminopropyl)triethoxysilane (APTES) and stirred for $18 \mathrm{~h}$. After $18 \mathrm{~h}$, the nanoparticles were obtained through centrifugation at $14000 \mathrm{rpm}$ for $20 \mathrm{~min}$ and washed with ethanol to store in ethanol.

CS-UCNRs@SiO2 modified with APTES expose the amine groups outward for conjugation with PEG polymers (HOOC-PEG-COOH) possessing carboxyl end groups with the reaction assisted by EDC and NHS. The PEGylated CS-UCNRs@SiO 2 was then covalently bind to the amino groups of antibodies (Clostridium polyclonal antibodies) for targeting the vegetative C. difficile.

Preparation of Au nanorods (NRs) and its surface modification: A $100 \mathrm{~mL}$ aliquot of a $0.5 \mathrm{mM}$

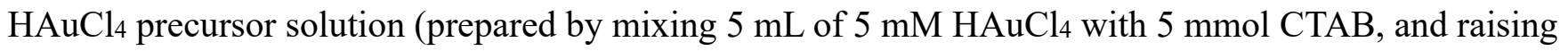
the volume to $50 \mathrm{~mL}$ with $\mathrm{H}_{2} \mathrm{O}$ ) was vigorously stirred, and $120 \mu \mathrm{L}$ of a $100 \mathrm{mM} \mathrm{AgNO}_{3}$ solution was added dropwise. After $5 \mathrm{~min}, 600 \mu \mathrm{L}$ of a $100 \mathrm{mM}$ ascorbic acid (AA) solution was added, followed by $40 \mu \mathrm{L}$ of a $1.6 \mathrm{mM} \mathrm{NaBH}_{4}$ solution, and the mixture was stirred for $150 \mathrm{~min}$. The obtained suspension 
was centrifuged at $13000 \mathrm{rpm}$ for $12 \mathrm{~min}$. The supernatant was discarded, and the precipitate was repeatedly washed with $\mathrm{H}_{2} \mathrm{O}$ under sonication, followed by centrifugation. Finally, the Au NRs were dispersed in $\mathrm{H}_{2} \mathrm{O}$.

To prepare the PEGylated Au NRs, 3-mercaptopropionic acid (MPA) was added to the CTAB capped $\mathrm{Au}$ NRs under stirring for $12 \mathrm{~h}$. The MPA capped Au NRs were then conjugated with $\mathrm{H}_{2} \mathrm{~N}-\mathrm{PEG}-\mathrm{NH}_{2}$ by the reaction assisted by EDC and NHS. Subsequently, the PEGylated Au NRs with amine end groups covalently bound to the -COOH groups of antibodies (Au NR-C. difficile and Au NR-anti-HER2) for antibody-guiding approach.

Cell culture: Human cell line from lung carcinomatous tissue, A549, was cultured in Dulbecco's modified eagle medium (DMEM, high glucose) supplied with non-essential amino acid and 10\% fetal bovine serum (FBS) in $5 \% \mathrm{CO}_{2}$ chamber mix with atmosphere at $37^{\circ} \mathrm{C}$. Normal human cell line from lung fibroblast, MRC-5, was cultured in Eagle's minimum essential medium (EMEM), containing Earle's balanced salt solution, non-essential amino acid, 2mM L-glutamine, $1 \mathrm{mM}$ sodium pyruvate, and 10\% FBS in $5 \% \mathrm{CO}_{2}$ chamber mix with atmosphere at $37^{\circ} \mathrm{C}$.

Cytotoxicity assay: Cytotoxicity assay was performed following the preparation protocol for MTT reagent. In brief, various concentration of CTAB or PEG caped Au NRs were cultured with A549 or MRC5 cells. A549 and MRC-5 were inoculated in the 96-well plate at a density of $5 \times 10^{3}$ and $10^{4}$, respectively. After $24 \mathrm{~h}$ of culture, various concentrations of Au NRs were added into culture medium for treatment of cells. Followed by removing the Au NRs-containing medium, formazan crystal in cells was dissolved by dimethyl sulfoxide (DMSO) and subjected to ELISA reader to measure the cell viability.

Temperature elevation profile upon laser irradiation: Au NRs with different Au concentrations in deionized water was added to the 96-well plates. The photoinduced temperature increase of the solutions was conducted using a CW NIR diode laser $(808 \mathrm{~nm})$ for 10 min irradiation at $0.5 \mathrm{~W} \mathrm{~cm}^{-2}$. The well was exposed to the laser light with a fixed beam size of $1 \mathrm{~cm}^{2}$. The change of temperature in solutions was determined by a thermocouple coupled with a digital thermometer (TES 1319A-K type).

A549 xenograft nude mouse model: Tumoral treatments were manipulated in accordance with the 
guideline of National Cheng Kung University (NCKU) Laboratory Animal Center (Tainan, Taiwan). Animals were cared with humanity in compliance with NCKU guidelines for maintenance and use of animals in research. A549 cells were implanted subcutaneously in the medium suspension of $10^{6}$ cells in $100 \mathrm{~L}$ and the inoculated nude mice (BALB/cAnN.Cg-Foxnlnu/CrlNarI) were cared and observed till the tumor dimeter exceeding $5 \mathrm{~mm}$, which is usually evaluated for central hypoxia of solid tumor.

For bioimaging mouse model, tumor xenograft and images of photoluminescent observation were performed in Chang Gung Memorial Hospital Laboratory Animal Center (Kaohsiung, Taiwan). The same experimental preparation and tumor volumes were used for bioimaging of the relevant UCNRs and PBS. For bioimaging demonstration, the relevant UCNRs were systematically delivered via tail vein injection with dosage of $20 \mathrm{mg}$ (Y composition) $\mathrm{kg}^{-1}$ determined by ICP-AES.

Efficacy for photothermal ablation of tumor was studied by injection of the relevant Au NRs and PBS intravenously into mice bearing tumors. Dosage were determined from Au mass using ICP-AES where $100 \mathrm{~g} \mathrm{Au}$ NRs per mouse was applied to study the photothermal treatment effect in vivo.

In vivo bioimaging and photothermal therapy: In vivo tumor photoluminescence was monitored using IVIS system with a cooling CCD optical device equipped with fluorescent filter sets (excitation/emission=980/800 nm) for detection of UCNRs NIR emission. Prior to detection, tumor bearing mice were injected systematically the relevant UCNRs at the dosage of $20 \mathrm{mg}(\mathrm{Y}) \mathrm{kg}^{-1}$. Images were taken at the time course of $1 \mathrm{~h}, 3 \mathrm{~h}, 5 \mathrm{~h}$, and $24 \mathrm{~h}$ after injection. Intensity of the emitted photoluminescence was statistically measured by the coupled image system to calculate the photons in regions of interest.

In vivo photothermal therapy, $100 \mathrm{~g}$ Au NRs per mouse was applied to achieve the photothermal treatments. Followed by $2 \mathrm{~h}$ after injection, tumor regions were irradiated with a $808 \mathrm{~nm}$ diode laser at $0.5 \mathrm{~W} \mathrm{~cm}^{-2}$ (beam size $\left.=1 \mathrm{~cm}^{2}\right)$ for $10 \mathrm{~min}$, which is in accordance with the in vitro temperature elevation studies. The tumor size was measured along the longest width and the corresponding perpendicular length. The tumor volume was calculated using the volume of an ellipsoid volume $=$ based on $4 \pi / 3($ length $/ 2 \times$ width/2 $\times \operatorname{depth} / 2)$. 
(a)

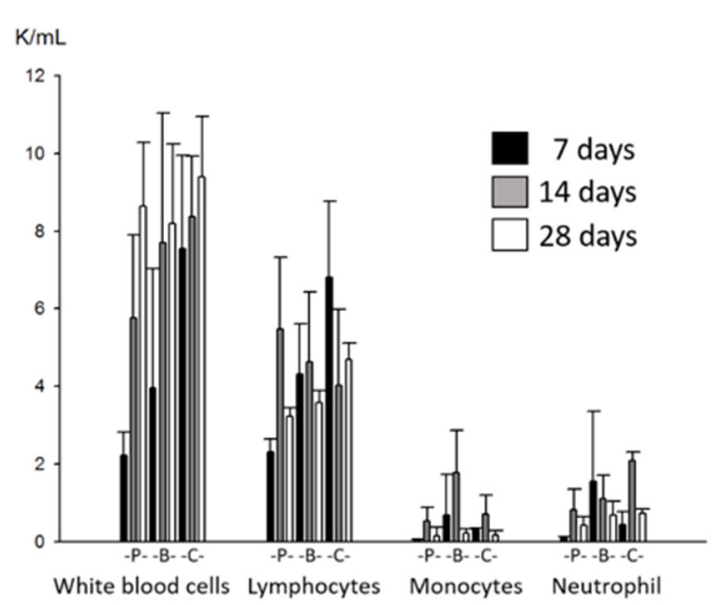

(b)

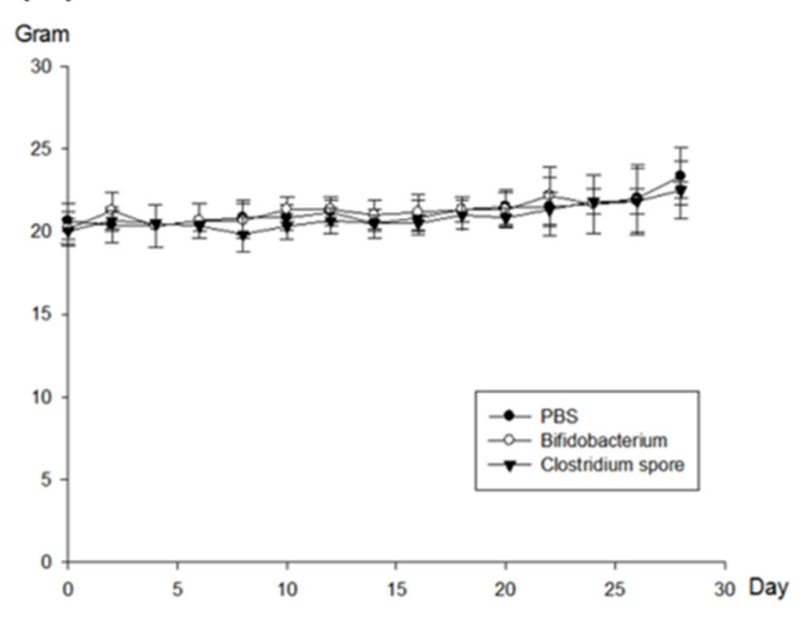

Figure S1. Biosafety of the bacteria in C57BL/6 mouse model. The respective vegetative $B$. breve and $C$. difficile spores were intravenous injection to mice for examination. (a) Observation of leukocytes counting for 4 weeks. P: injection of PBS as the control group; B: injection of vegetative $B$. breve; C: injection of $C$. difficile spores. (b) Body weights of the mice monitored for 4 weeks. 


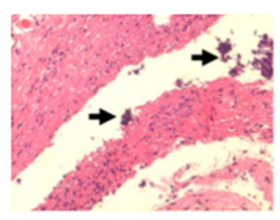

IT-T

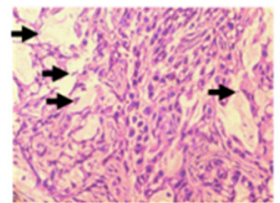

IV-T

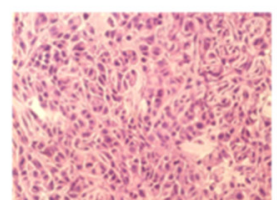

Ct-T

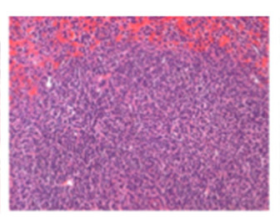

IT-S

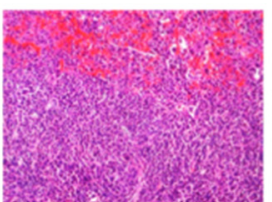

IV-S

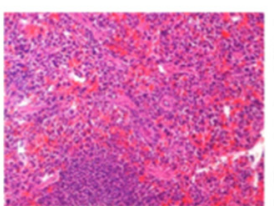

Ct-S

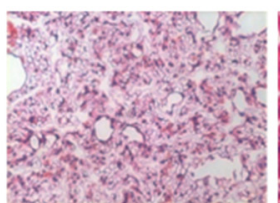

IT-Lu

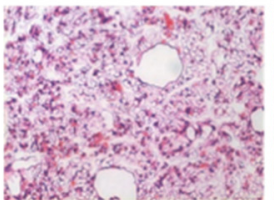

IV-Lu

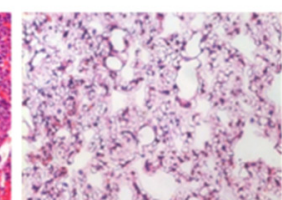

Ct-Lu

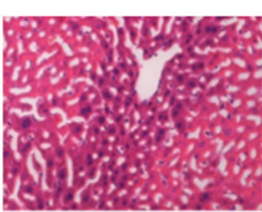

IT-Li

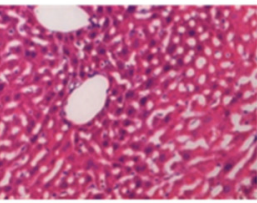

IV-Li

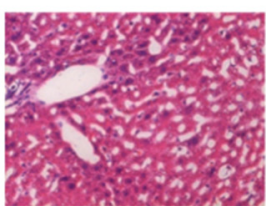

Ct-Li

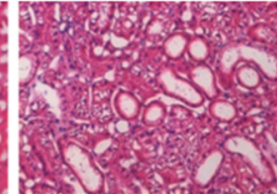

IT-K

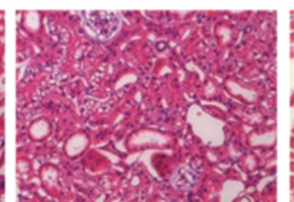

IV-K

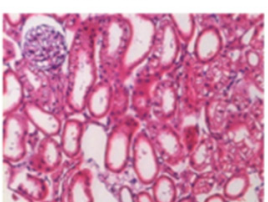

Ct-K

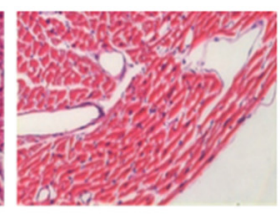

IT-H

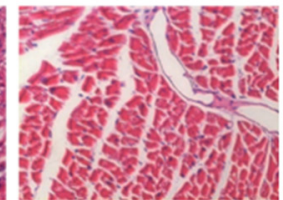

IV-H

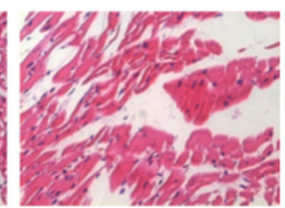

Ct-H

Figure S2. Bacterial distribution of intratumoral and intravenous injection of Clostridium spores. Hematoxylin and eosin stained histological images of the tissues from tumor and five major organs (spleen, lung, liver, kidney, heart) from the mice bearing xenograft A549 tumors subjected to the injection of $C$. difficile spores. T: tumor; IT: intratumoral injection; IV: intravenous injection; Ct: control; S: spleen; Lu: lung; Li: liver; K: kidney; $\mathrm{H}$ : heart. The arrows indicate the presence of the bacteria. 


\section{(a)}
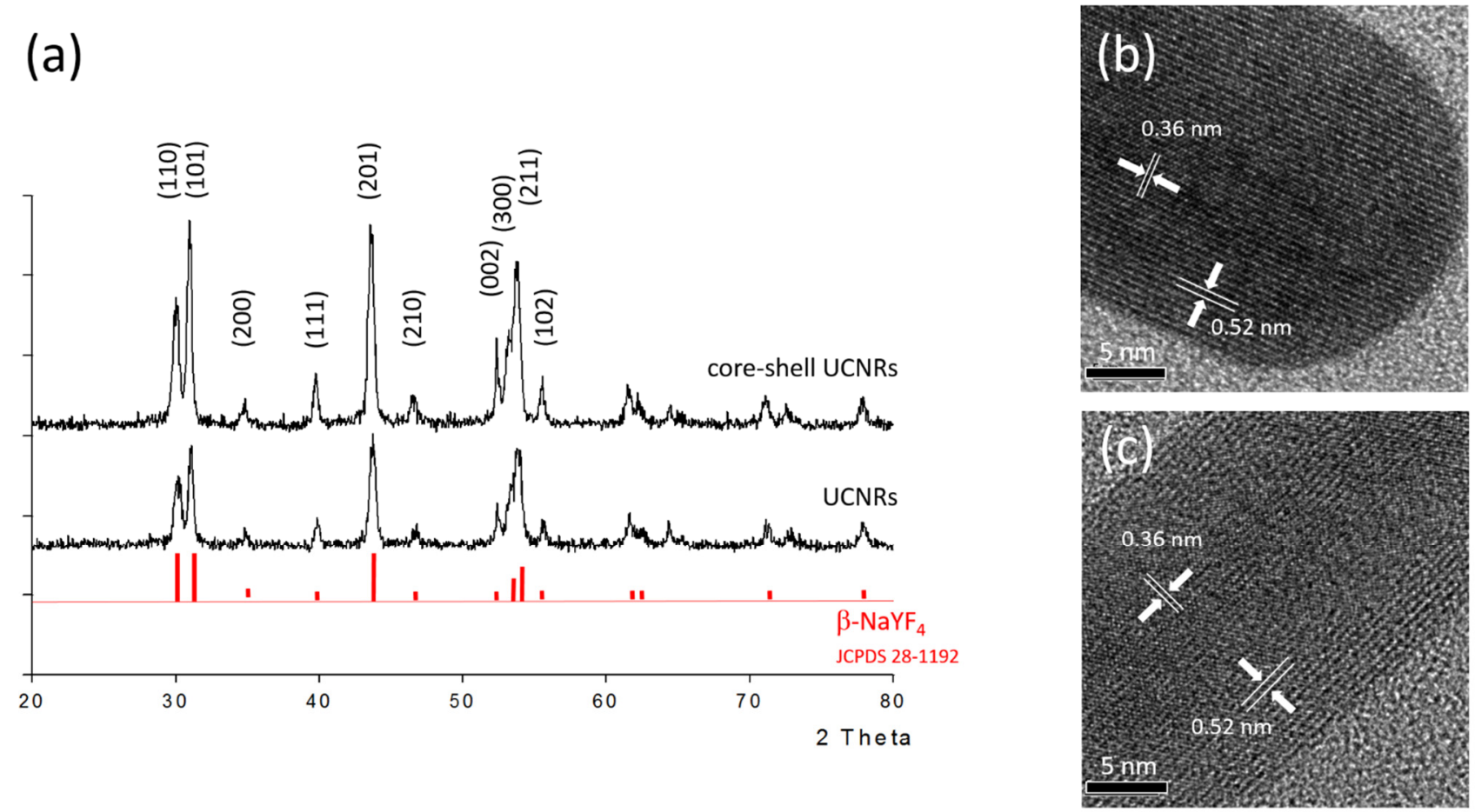

Figure S3. Characterization of UCNRs and core-shell UCNRs. (a) XRD patterns of UCNRs and coreshell UCNRs indexed to the hexagonal phased $\mathrm{NaYF}_{4}$ crystals (JCPDS standard card no. 28-1192). HRTEM images of the crystal and lattices showing (100) planes with $d$-spacing of $0.52 \mathrm{~nm}$ and (001) planes with $d$-spacing of $0.36 \mathrm{~nm}$, corresponding to the beta form $\mathrm{NaYF}_{4}$ crystal for both (b) UCNRs and (c) core-shell UCNRs. 


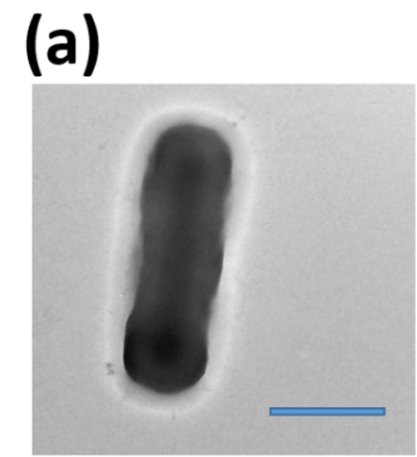

$10^{8} \mathrm{CFU} / 10 \mathrm{ppm} / 1 \mathrm{ml}$

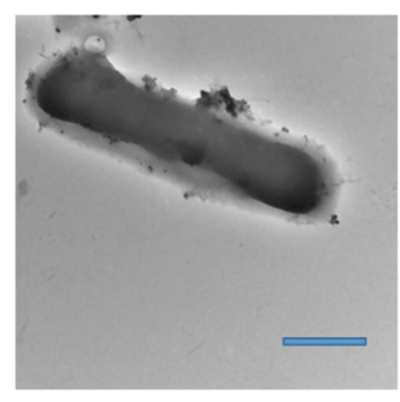

$10^{8} \mathrm{CFU} / 50 \mathrm{ppm} / 1 \mathrm{ml}$

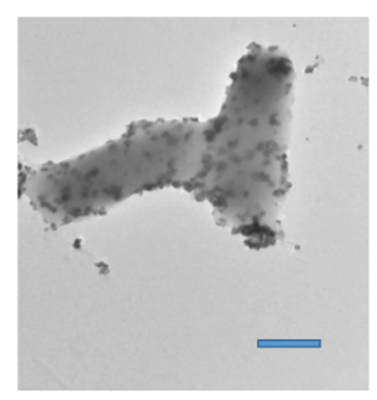

$10^{8} \mathrm{CFU} / 100 \mathrm{ppm} / 1 \mathrm{ml}$

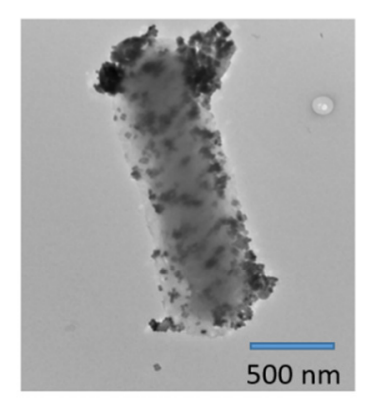

$10^{8} \mathrm{CFU} / 500 \mathrm{ppm} / 1 \mathrm{ml}$

(b)
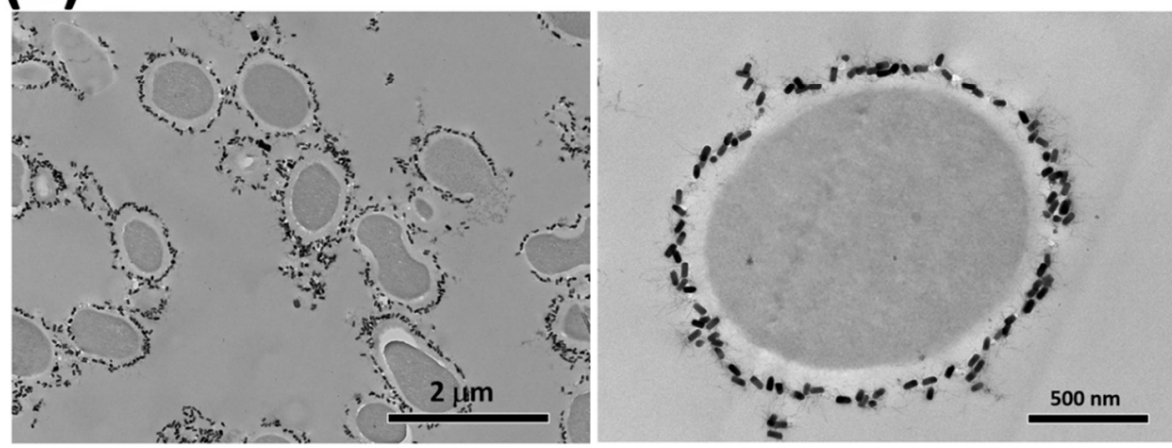

Figure S4. Electrostatic deposition of the ligand free core-shell UCNRs on the surface of $B$. breve. (a) TEM images of the ligand free core-shell UCNRs/B. breve complexes in various ligand free core-shell UCNRs concentrations (ppm). The gray region on the surface of ligand free core-shell UCNRs/B. breve exhibits the thick biofilm. As seen in figures, the amount of the deposited UCNRs on bacterial surface increases as UCNRs concentration. The resulting ligand free core-shell UCNRs/B. breve complexes were able to experience several times of PBS wash without losing UCNRs from bacterial surface. (b) CryoTEM images show the ligand free core-shell UCNRs attached on the B. breve bacterial cell walls. 

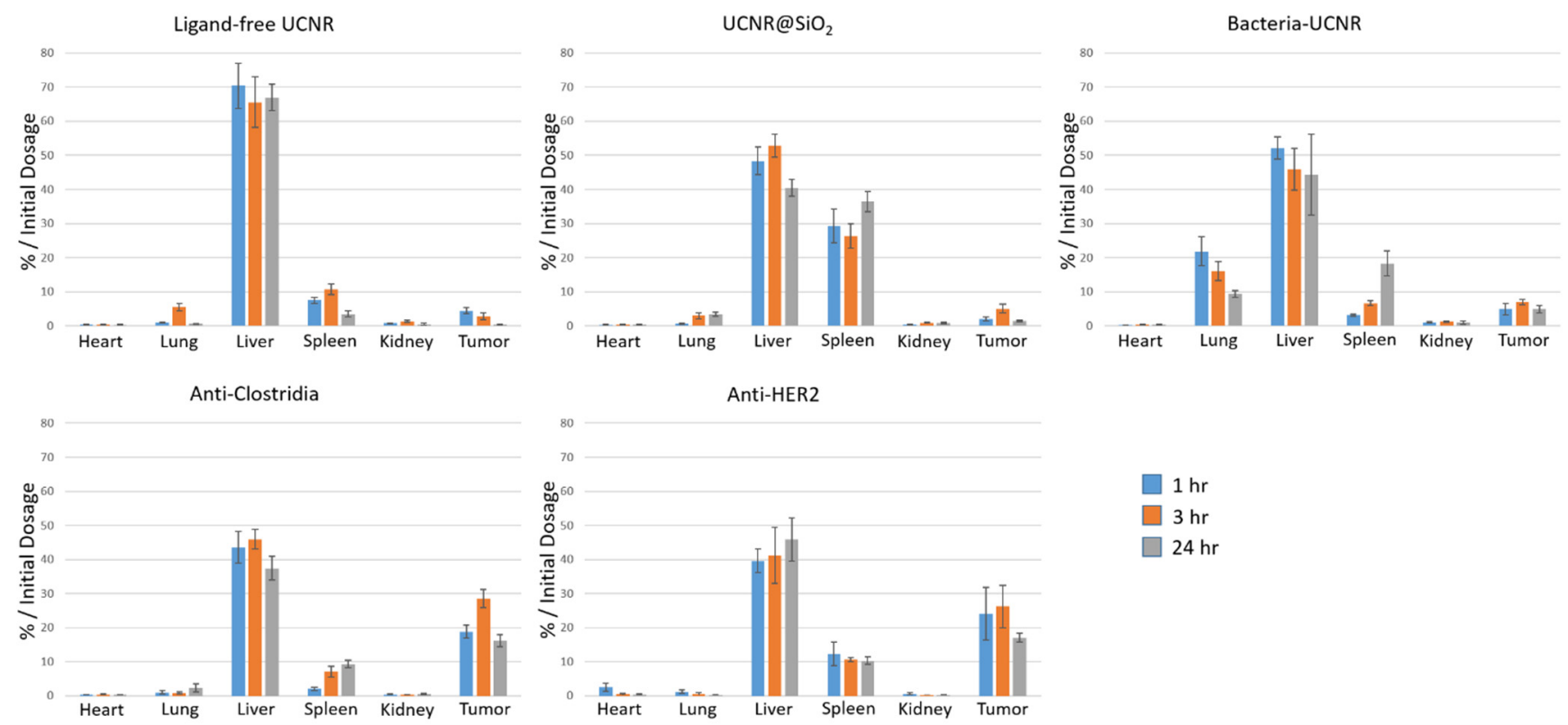

Figure S5. Biodistribution of the UCNRs under different forms in A549 xerographic tumor model. Organs from the mice at different time course were sacrificed and excised after intravenous injection of UCNRs. Tissues were homogenized and the quantity of UCNRs was determined by atomic absorption spectrometer $(\mathrm{n}=3)$. 


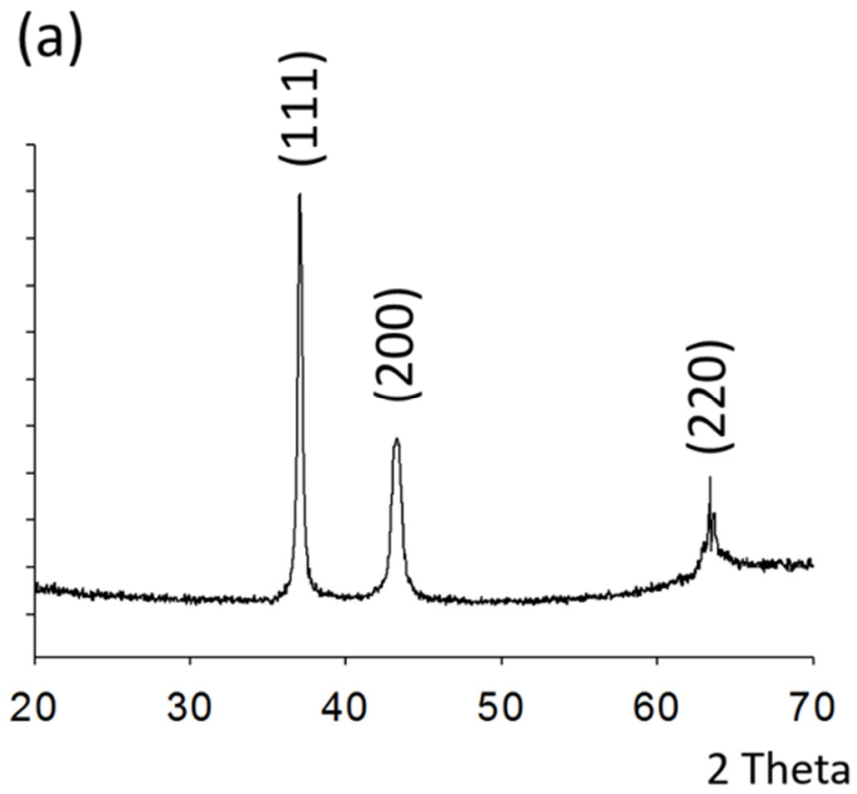

(b)

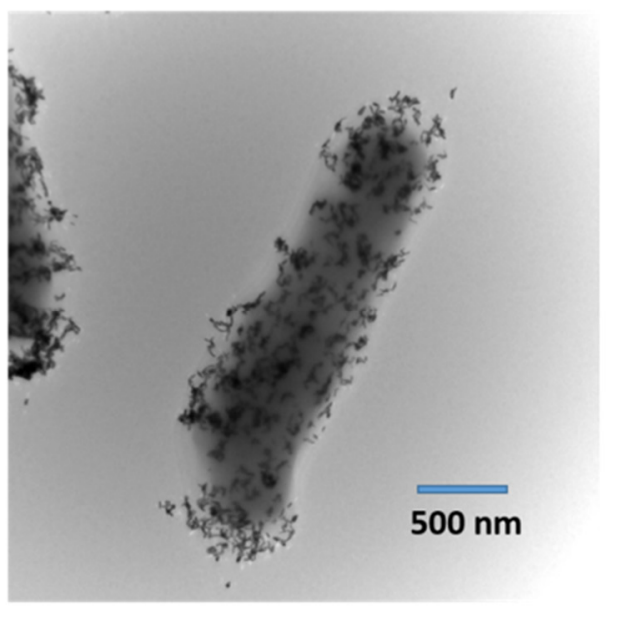

Figure S6. Characterization and electrostatic deposition of Au NRs. (a) XRD pattern of Au NRs with the patterns at $38.2,44.5$, and $64.9^{\circ}$ corresponding to (111), (200), and (220) reflections, respectively. (b) Deposition of positively charged $(+26 \mathrm{mV})$ cystamine-capped Au NRs on the surface of $B$. breve. 
(a)

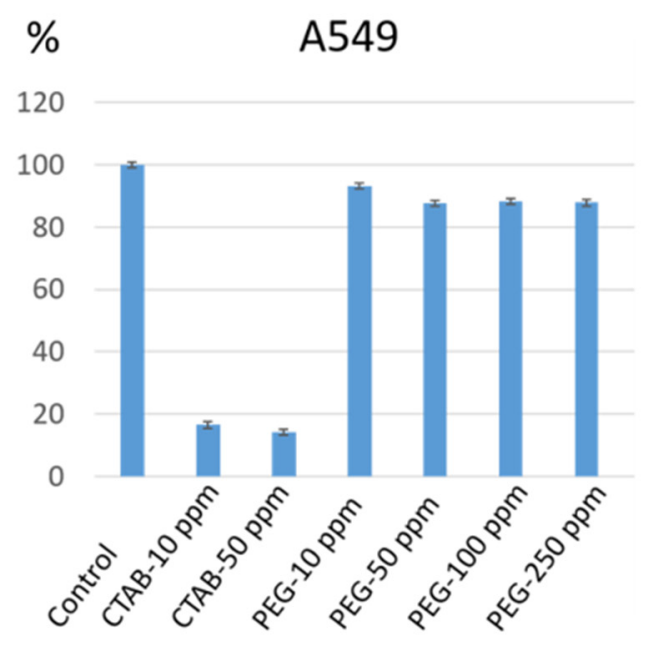

(b)

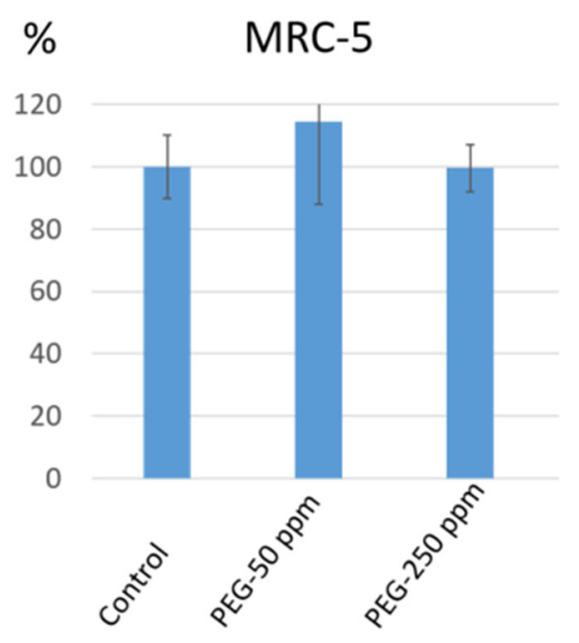

Figure S7. Cell viabilities of A549 and MRC-5 cells treated with various concentrations of Au NRs. MTT assays to examine the cellular growth cultured with various Au concentrations (ppm) for $24 \mathrm{~h}$. (a) The toxic CTAB-capped Au NRs showed the significant reduction in A549 cells viability at low $10 \mathrm{ppm}$, while the PEGylated Au NRs exhibited biocompatibility up to $250 \mathrm{ppm}$. (b) Normal lung fibroblast cells, MRC5, were treated to show the susceptibility of PEGylated Au NRs. All of the date were obtained in triplicate. 


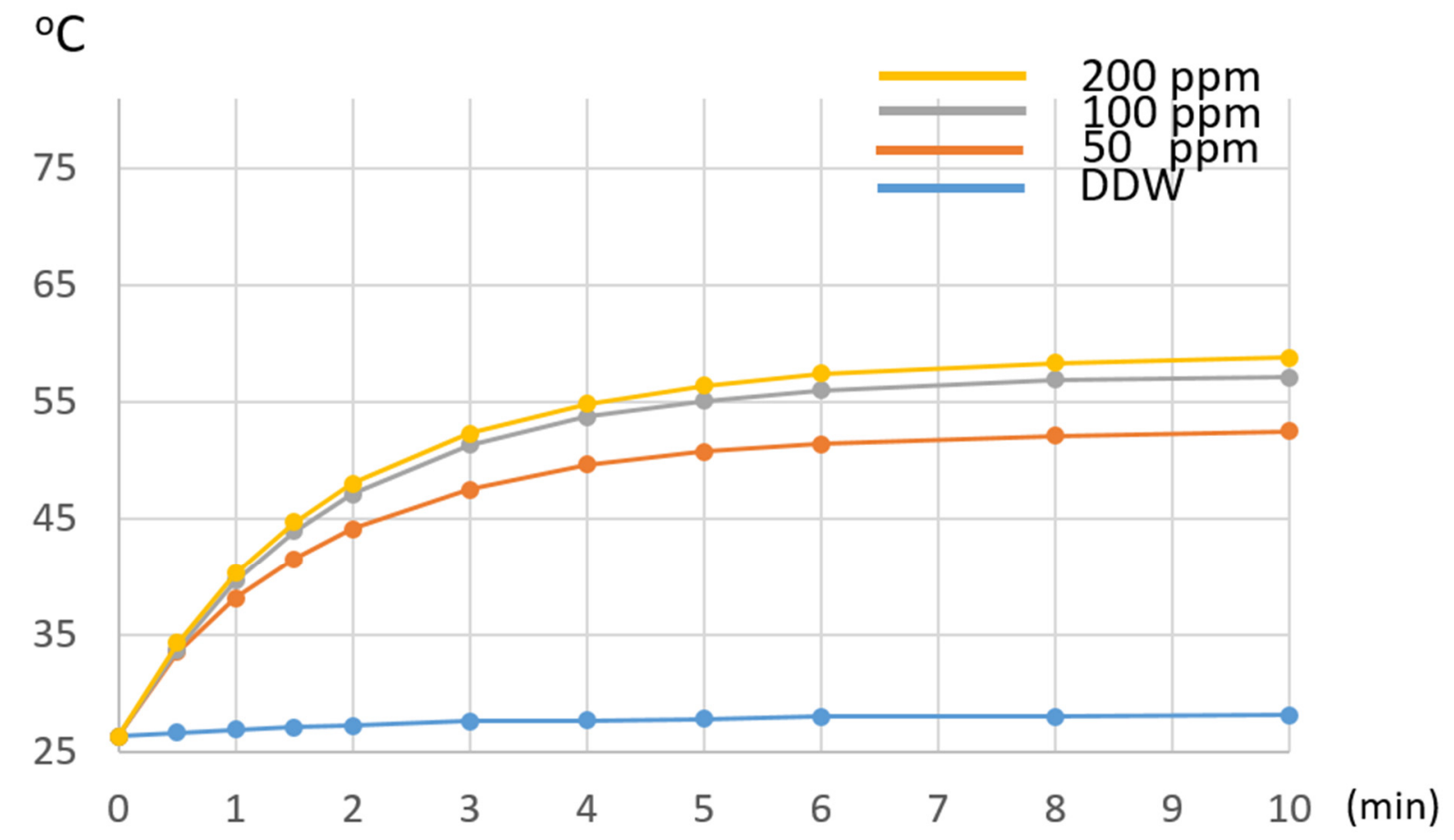

Figure S8. Temperature elevation curves of PEGylated Au NRs. PEGylated Au NRs were subjected to $808 \mathrm{~nm}$ diode laser irradiation at laser intensity of $0.5 \mathrm{~W} / \mathrm{cm}^{2}$ for $10 \mathrm{~min}$. No temperature change was observed for pure water upon laser irradiation. Larger PEGylated Au NRs concentration resulted in higher temperature elevation. 
(a)
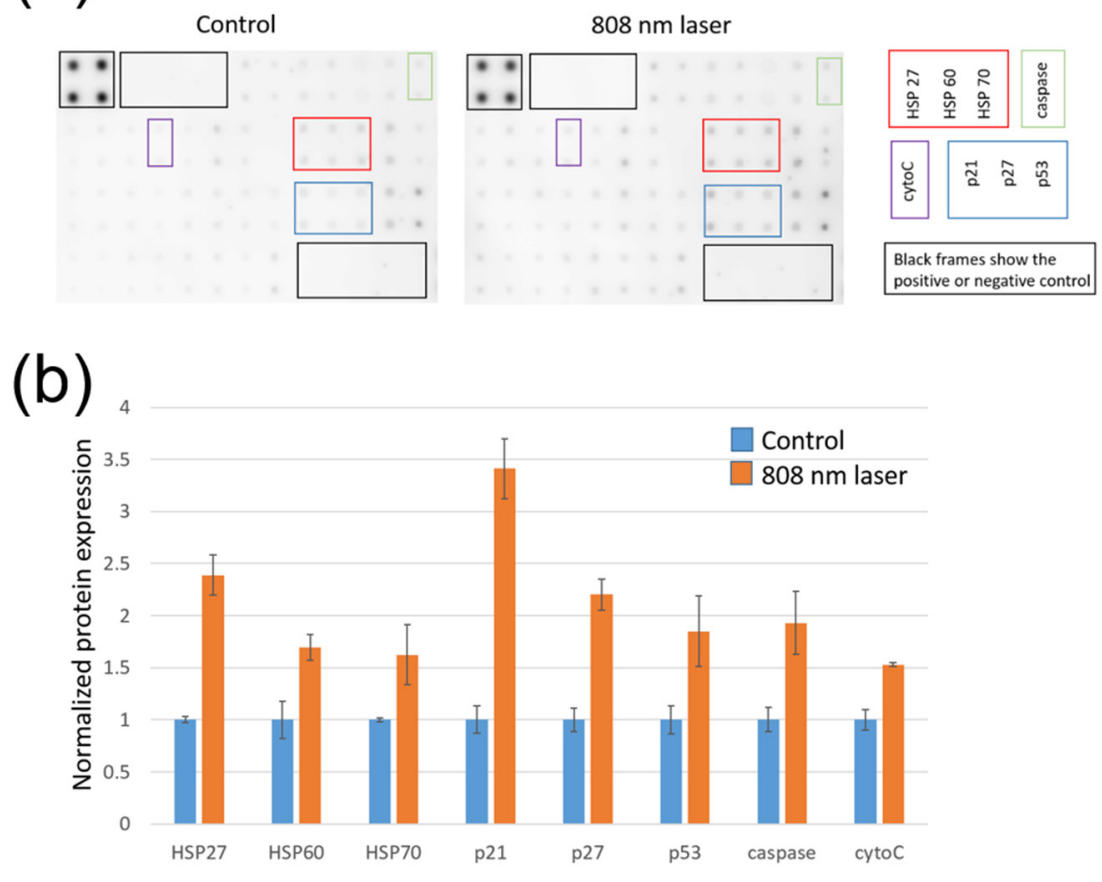

(c)

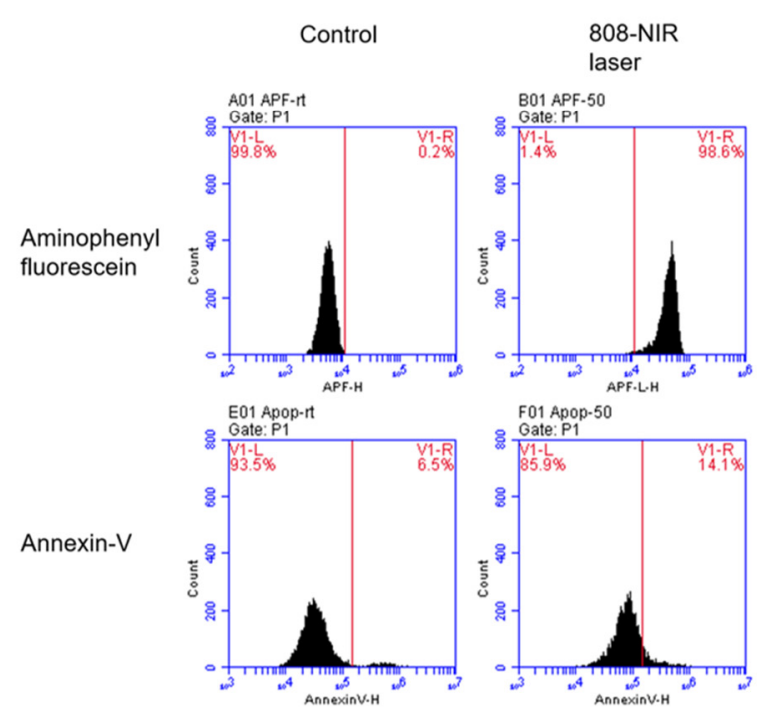

Figure S9. Evidences for hyperthermia-induced apoptosis. (a) Antibody arrays (provided by RayBiotech, Inc., Norcross, Georgia) were used to detect the apoptosis signaling proteins. (b) Statistic results for the induced apoptosis signaling proteins. (c) Flow cytometry profiles showing the hyperthermia-induced disruption of ROS homeostasis detected by aminophenyl fluorescein and the early signal for the programmed cell death detected by annexin-V. 